interacting moments to be addressed. Challenging blind spots in the building may require a higher staffing ratio. High staff turnover makes demands on the routines for preparing new employees for their duties. Improving quality requires involving both those who receive and provide complex interventions, combining both a top-down and bottom-up perspective. The KvIP process makes this possible.

Do not be put off by the large number of standards. They function, but not on their own. They are embedded in a process to facilitate development over time. We believe that the routines in place with KvIP enable units to be safer places of work, with secure patient contact, in healthy environments which have integrated the current demands from both political committees and the owners of the institutions with good clinical practice.

The annual report from KvIP summarises the overall findings. ${ }^{5}$

\section{Author contributions}

S.R.W. took the lead in writing the manuscript, with input and support from K.E.A.L. Both authors provided critical feedback and contributed to the final version.

\section{Funding}

This research received no specific grant from any funding agency, commercial or not-for-profit sectors.

\section{Declaration of interest}

None.

ICMJE forms are in the supplementary material, available online at https://doi.org/10.1192/bji.2021.7.

\section{Reference}

1 College Centre for Quality Improvement. Child and Adolescent Community Teams - CAMHS. Royal College of Psychiatrists, 2020 (https://www.rcpsych.ac.uk/improving-care/ccqi/qualitynetworks-accreditation/child-and-adolescent-community-teamsqncc).

2 College Centre for Quality Improvement. Quality Network for Inpatient CAMHS - QNIC. Royal College of Psychiatrists, 2020 (www.rcpsych.ac.uk/improving-care/ccqi/quality-networksaccreditation/child-adolescent-inpatient-services).

3 Akuttnettverket [The Emergency Network]. KvIP barn og unge [KvIP for children and young people]. Akuttnettverket, 2020. Available from: www.akuttnettverket.no/kvip-barn-og-unge/492.

4 Jacobs BW, Green J, Beecham J, Kroll L, Dunn G, Tobias C, et al Two and a Half Thousand Hours: The Children and Young Persons Inpatient Evaluation Study (CHYPIE) into Process and Outcome of Inpatient Child and Adolescent Psychiatry. Department of Health, 2004.

5 Akuttnettverket [The Emergency Network]. Årsrapporter for KvIP [Annual reports for KvIP]. Akuttnettverket, 2020. Available from: https://akuttnettverket.no/prosjekter/arsrapporter-for-kvip.

\title{
COUNTRY PROFILE \\ Towards community care: Qatar's rapidly evolving mental health landscape
}

\author{
Barry Solaiman ${ }^{1} \odot$ and Suhaila Ghuloum ${ }^{2}$ ๑
}

${ }^{1}$ Assistant Professor of Healthcare Law, Hamad Bin Khalifa University Law, Doha Qatar, email: bsolaiman@hbku. edu.qa

${ }^{2}$ Senior Consultant Psychiatrist, FRCPsych, Department of Psychiatry, Hamad Medical Corporation, Doha, Qatar, email: sghuloum@hamad.qa

Keywords. Psychiatry and law; community care: mental health: Qatar; mental health strategy.

First received 3 Nov 2020 Final revision 17 Jan 2021 Accepted 16 Feb 2021

doi:10.1192/bji.2021.21

(c) The Author(s), 2021. Published by Cambridge University Press on behalf of the Royal College of Psychiatrists. This is an Op , distributed under the terms of the Creative Commons Attribution licence (http://creativecommons.org/ licenses/by/4.0/), which permits unrestricted re-use, distribution, and reproduction in any medium,
An undercurrent of change is occurring in Qatar's approach towards mental healthcare. In the past 5 years, significant attention has been given to community care initiatives. There is much progress to be made, but the provision of psychiatric support outside of hospitals, the launch of several community services and the tackling of the associated social stigma represent a marked step away from the norm that has usually pervaded in the region. This article analyses these changes and identifies the challenges that remain.

In recent years, several authors have contributed to a burgeoning body of publications on mental health in Qatar. ${ }^{1-5}$ This article builds on this expanding literature by assessing Qatar's progress towards community care as a method for dealing with mental health concerns in the country. This assessment is particularly important at this stage. Healthcare leaders have been determined to enhance community mental healthcare by moving away from institution-based care requiring hospital admission. Although the availability of mental health services remains limited in Qatar, the intention is to move towards a more robust offering of community-based services around the country. ${ }^{6}$ Several factors underlie a greater focus on implementing, integrating and utilising mental health services. These include the National Mental Health Strategy (NMHS), Law No. 16 of 2016 on Mental Health, and community-based initiatives. This paper outlines these developments and identifies the remaining challenges. The intention is to establish a comparative anchor for future assessments following the expiry of the current NMHS in 2022. This work was undertaken in Qatar.

\section{A strategy for community care}

The first goal of the National Health Strategy (NHS) is to have a comprehensive world-class healthcare system, with mental health an integral 
part of it. The initial incarnation of the NMHS was the 2013-2018 Strategy, which evolved into the National Mental Health \& Wellbeing Strategic Framework 2019-2022. The Strategy aimed to ensure access to the right care, at the right time and in the right place. The focus was on shifting from hospital-based care to community mental health service $(\mathrm{CMH})$ delivery. ${ }^{7}$ Under the initial Strategy, a number of key achievements were made. These included a new model for primary care; psychological support clinics in primary care; new child, adolescent and women's mental health services; and new CMH facilities and community teams. ${ }^{8}$ Mental health training was provided to family physicians and primary care doctors; a pilot was initiated in three primary care centres to treat mild-to-moderate anxiety and depression, which are the two most common mental health conditions in Qatar, using standardised screening tools, management guidelines and indications for referral to secondary care. ${ }^{3}$

The success of this pilot encouraged a wider enrolment of the programme to all primary care facilities. The focus on 'well-being' under the extended framework indicates the elevation of importance given to mental healthcare beyond hospital admission. This importance is reflected in priority being given to 'high-quality' access to community care services moving forward. ${ }^{8}$ Overarching the NMHS is Qatar's general NHS 2018-2022. ${ }^{6}$ The NHS encompasses a broader vision towards well-being through active engagement of an individual in society and contributing to the community. ${ }^{6}$

\section{The evolution of the law}

Another development has been the drafting of Law No. 16 of 2016 on Mental Health. The Law has yet to be implemented because the organisational structure required to start implementation remains vague. Challenges around implementing the law (especially the community treatment order provisions within it) and balancing patient autonomy with family interventions and safety for the patient, society and healthcare providers remain to be seen. As such, the Law's influence will largely be determined by the resolution of these matters.

A concerted effort could yield significant progress. The Law codifies community care under the rubric of citizen 'rights'. Article 2 stipulates which institutions shall provide community care services (hospitals, clinics and any other place providing community care services). Currently, CMH teams provide home visits for patients through their outreach programme. However, they are not authorised to provide treatment against patients' will, regardless of their capacity to consent or the risks they may impose. It is critical that moves towards implementation delineate the boundaries of community care services and the role of medical professionals. There is an opportunity for the right to community care to be defined under the rubric of the Law.

The type of care captured by the Law is distinct from other community care services which have recently developed for mild-to-moderate mental health needs.

\section{Broadening access to the general population}

Strategies for a more comprehensive provision of community care have been building for several years. This emphasis is manifested in the Annual Symposium for Community Mental Health Services, which has been conducted for 5 years. One purpose of the symposium is to propose strategies for promoting access to mental health and well-being services. The target is for $40 \%$ of services to be offered through primary and community care settings by 2022 .

Prior to the COVID-19 pandemic in 2020, strategies for greater community care were already being deployed. The first CMH hub was opened in 2015, covering west Doha, and more recently a second one opened at $\mathrm{Al}$ Wakrah to cover the south, with plans for two others to target all geographical areas of the country. These hubs are run by a multidisciplinary team consisting of psychiatrists, nurses, occupational therapists and a social worker, who are trained on the job in principles of CMH delivery. Some staff involved had received a period of training abroad, mainly in the UK, Ireland and Australia. The of an outreach component, day care and a small residential service. Patients are visited by a community mental health nurse, supervised by a psychiatrist, to conduct mental state and risk assessments, administer depot medication, monitor adherence to treatment plans, support activities of daily living, and address family issues and other relevant aspects of care as needed. Subspecialty CMH services have been started for the geriatric, learning disability and forensic populations. Furthermore, integration of mental health into primary care services has started, with psychiatry clinics run by consultant psychiatrists at two primary healthcare centres. ${ }^{10}$ The healthcare system in Qatar is heavily subsidised. Community mental healthcare is thus provided free of charge for Qatari patients. Non-nationals are required to pay $20 \%$ of the cost of medication, but many patients receive exemption from payment because of the chronicity of their illness.

In 2018, a website was launched providing mental health support, called 'Your Mind Matters', and a referral-based community service called Enaya Community Care Center was launched. This strategy also involved working with primary health centres to provide assessments and consultations for patients with mild-to-moderate mental health needs. ${ }^{11}$ The Minister of Public Health released a public Guide to Mental Health Services in 2019 detailing available services. 
Following the COVID-19 pandemic, there has been an acceleration in the provision of services. For example, a Mental Health Service Helpline was set up in 2020 and had received 3000 calls by April. ${ }^{12}$ In-person services were available to those not wishing to speak over the phone. Mental health guides were distributed to construction workers, greater coordination efforts were made with primary health centres, and the Mental Health Friends Association (Weyak) ran programmes throughout the pandemic to assist those in need of mental health support. ${ }^{13}$ The introduction of telepsychiatry as an urgent need during COVID-19 proved very successful. Patients were contacted by phone for out-patient appointments. Many expressed an appreciation of this option, as it addressed the high level of stigma in the community as well as practical challenges in attending clinics in person. It is evident that telepsychiatry will continue to expand after the pandemic.

Such efforts extend beyond the health sector to educational institutions. Universities, in particular, have recognised the importance of providing mental health services for students. In part, this is influenced by the number of American branch campuses based in the country, where the culture of attention towards mental health issues has been transposed on the ground in Qatar. Northwestern, Georgetown, Weill Cornell Medicine, Texas A\&M, Virginia Commonwealth and others provide counselling services to students. This effort extends to the major local universities such as Qatar University and Hamad Bin Khalifa University (HBKU). Qatar University offers a Student Counselling Service with psychologists and psychiatrists from mental health services. HBKU offered free online consulting sessions for staff and students during the COVID-19 pandemic, led by a senior consultant from a local hospital. ${ }^{14}$

\section{The challenges moving forward}

Establishing CMH services has faced many obstacles over the years. People would refuse home visits from hospital staff wearing uniforms and cars bearing the hospital logo. That hesitance made simple changes quite challenging to implement. The publication of the NMHS provided significant support for implementing change and enhancing services. Nevertheless, more public awareness is needed regarding the availability of community services, and effort is still needed to tackle stigma. At the same time, public attitudes towards mental illness need to be measured and compared with previously published data. This will help to evaluate the influence of ongoing awareness efforts and guide future ones. A notable increase in adherence to out-patient appointments occurred during the COVID-19 pandemic as telepsychiatry was implemented instead of in-person attendance. This may reflect the public's preference, especially in the context of high levels of stigma. Expanding the utilisation of telepsychiatry may, therefore, indicate the path forward.

Indeed, reluctance among locals to seek mental healthcare at the main hospital persists. The current $\mathrm{CMH}$ services are understaffed. Greater resources are needed in terms of staffing, transportation and structural facilities to ensure coverage of all geographical areas. There is a need to recruit psychologists and social workers to ensure that a more comprehensive biopsychosocial approach to treatment is adopted. To expand services across the country, a significantly larger number of mental-health-trained nurses must be recruited. The service is yet to provide comprehensive mental healthcare, including psychotherapy, rehabilitation and vocational training, as well as residential care for an increasing number of patients with chronic illness who need longer-term care.

Qatar has a highly multi-ethnic population; communication with patients from different backgrounds and with different languages spoken is a challenge in a medical specialty primarily based on communication. Addressing this challenge requires targeted recruitment and investment in technology to support communication efforts.

Local cultural and spiritual beliefs must be considered in a successful CMH service. Many of the treatment models currently used are predominantly Western-based; these need to be adapted to the local context for them to be accepted by the public.

Finally, the law was published in the official gazette in November 2016 and came into force 60 days later. However, the procedures required for its implementation are yet to be established within the health sector. The Mental Health Law must move towards implementation to enshrine the mandate for establishing community care services while reinforcing the rights of citizens to such services.

\section{Conclusion}

The developments noted here signal an escalation in the attention given to and availability of $\mathrm{CMH}$ services in recent years. Improvements have been made at the policy, legal and implementation levels which are unprecedented. However, sight must not be lost of the challenges that remain. These factors will require reappraisal following the next strategy in 2022 to determine the progress made.

\section{Author contributions}

B.S. developed the concept for the paper and its focus, had primary responsibility for drafting the article, has joint final approval of the version to be published, and is accountable for all aspects of the work. S.G. provided information for the article, drafted sections on the practical challenges on implementing community care, has joint final approval of the version to be published, and is accountable for all aspects of the work.

\section{Funding}

This research received no specific grant from any funding agency, commercial or not-for-profit sectors 
Declaration of interest

None.

\section{References}

1 Ghuloum S, Ibrahim MA. Psychiatry in Qatar. Int Psychiatry 2006; 3(4): 16-8.

2 Abou-Saleh MT, Ibrahim MA. Mental health law in Qatar. Int Psychiatry 2013; 10(4): 88-90.

3 Sharkey T. Mental health strategy and impact evaluation in Qatar. BJPsych Int 2017; 14(1): 18-21.

4 Elzamzamy K, Alsiddiqi A, Khalil A, Elamin H, Abdul Karim M, Wadoo O. Newspaper depiction of mental and physical health in Qatar. BJPsych Int 2020; 18(1): 12-15.

5 Wadoo O, Ahmed MAS, Reagu S, Al Abdulla SA, Al Abdulla MAYA. Primary care mental health services in Qatar. BJPsych Int 2020; 18(1): 15-18.

6 MOPH. National Health Strategy 2018-2022: Our Future Our Health. Ministry of Public Health (Qatar), 2018.

7 General Secretariat of the Supreme Council of Health. Qata National Mental Health Strategy, Changing Minds, Changing Lives 2013-2018. Ministry of Public Health, 2013 (https://www. moph.gov.qa/health-strategies/national-mental-health-strategy).

$8 \mathrm{MOPH}$. Summary of National Mental Health \& Wellbeing Strategic Framework 2019-2022. Ministry of Public Health, 2019 (https:/l www.moph.gov.qa/english/strategies/Supporting-Strategies-and-
Frameworks/SummaryNationalMentalHealthFramework2019. 2022/Pages/default.aspx)

9 Hamad Medical Corporation. 5th Annual Symposium for Community Mental Health Services in Qatar Highlights Mental Health Law Advancements. Hamad Medical Corporation, 2019 (https://www.hamad.qa/EN/news/2019/april/Pages/5th-AnnualSymposium-for-Community-Mental-Health-Services-in-QatarHighlights-Mental-Health-Law-Advancements.aspx).

10 Saeed E, Wadoo O, Ouanes S. Community mental health services in Qatar. In Mental Health in Qatar: Challenges and Prospects (eds A Haque, L Gilstrap, S Ghuloum): 364-86. Cambridge Scholars, 2020.

11 Gulf Times. Community Mental Health Symposium Highlights Development of Psychotherapy Services. Gulf Times, 2019 (https://m.gulf-times.com/story/629935/Community-mentalhealth-symposium-highlights-development-of-psychotherapyservices).

12 Peninsula. Mental Health Helpline Service Receives 3000 Calls. The Peninsula, 2020 (https://thepeninsulaqatar.com/article/25/ 04/2020/Mental-Health-Helpline-Service-receives-3000-calls)

13 Varghese J. Qatar Provides Significant Mental Health Support during Covid-19. Gulf Times, 2020 (https://www.gulf-times.com/ story/664125/Qatar-provides-significant-mental-health-supportduring-Covid-19).

14 Hamad Bin Khalifa University. HBKU Offers Counseling to Community with Concerns About COVID-19. HBKU, 2020 (https://www.hbku.edu.qa/en/news/hbku-offerscounseling).

\title{
SPECIAL PAPER
}

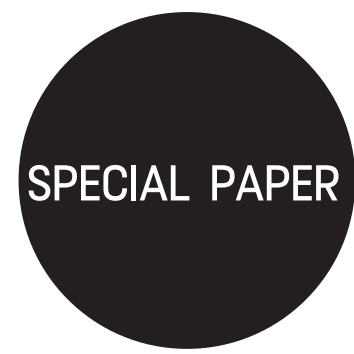

\section{Transitioning to community-based mental healthcare: reform experiences of five countries}

\author{
Ben Hoi-Ching Wong, ${ }^{1}$ ๑ Eka Chkonia, ${ }^{2}$ Lilia Panteleeva, ${ }^{3}$ Irina Pinchuk, ${ }^{4}$ \\ Dejan Stevanovic, ${ }^{5}$ Ali Evren Tufan, ${ }^{6}$ Norbert Skokauskas ${ }^{7}$ and \\ Dennis Ougrin ${ }^{8} \odot$
}

'Lewisham CAMHS, South London and Maudsley Mental Health NHS Trust, UK, email hoi_ching.wong@kcl.ac.uk

${ }^{2}$ Department of Psychiatry, Tbilis State Medical University, Georgia

${ }^{3}$ Department of Medical Psychology, Psychiatry and Psychotherapy, Kyrgyz-Russian Slavic University Faculty of Medicine, Kyrgyzstan

${ }^{4}$ Institute of Psychiatry, Taras Shevchenko National University of Kyiv, Ukraine

${ }^{5}$ Psychiatry Department, Clinic for Neurology and Psychiatry for Children and Youth, Serbia

${ }^{6}$ Department of Child and Adolescent Psychiatry, Faculty of Medicine, Bolu Abant Izzet Baysal University, Turkey

${ }^{7}$ Regional Centre for Child and Youth Mental Health and Child Welfare of Central Norway, Department of Mental Health, Norwegian University of Science and Technology, Norway
Following the growing global focus on deinstitutionalisation in the past $\mathbf{5 0}$ years, accessible community mental health services was a highlighted commitment in the European Mental Health Action Plan 2013-2020 to improve well-being of patients and families. The progress of transition has been uneven in some Eastern European countries. This paper aims to update and reflect on the examples of five countries across the region.

Healthcare systems in Eastern Europe are diverse and often reflect historical legacies dating back to the Cold War era. Countries in the Western Bloc (e.g. Turkey) were some of the first to adopt population-oriented systems. States from the former Yugoslavia (e.g. Serbia) relied on sectorised, hospital-based psychiatric care. Former Soviet countries (e.g. Ukraine, Georgia and Kyrgyzstan) were influenced by the Semashko model, with highly centralised healthcare infrastructure, funding and staffing. Despite their different backgrounds, all countries have made respectable efforts to reform mental healthcare in the recent years, motivated by the growing need for affordable and efficient community mental healthcare.

\section{Establishing community centres in Serbia}

The National Strategy for Development of Mental Health Care, approved in 2007 in Serbia, identified deinstitutionalisation and the development of community services as the main aspects in the reform of psychiatry care in the country. ${ }^{1}$ It was recognised that community mental healthcare should be based mainly at centres for mental health (centri za mentalno zdravlje), which would provide all-inclusive mental healthcare for persons with psychiatric disorders. Five centres for mental health have been opened in Serbia since 